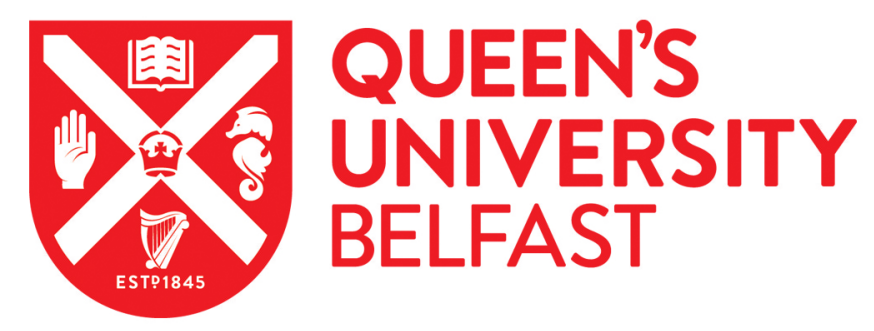

\title{
Identification of protein-polysaccharide nanoparticles carrying hepatoprotective bioactives in freshwater clam (Corbicula fluminea Muller) soup
}

Yu, Z., Gao, G., Wang, H., Ke, L., Zhou, J., Rao, P., Chen, T., Peng, Z., Zou, J., \& Luo, S. (2020). Identification of protein-polysaccharide nanoparticles carrying hepatoprotective bioactives in freshwater clam (Corbicula fluminea Muller) soup. International Journal of Biological Macromolecules.

https://doi.org/10.1016/j.ijbiomac.2020.02.105

\section{Published in:}

International Journal of Biological Macromolecules

\section{Document Version:}

Peer reviewed version

Queen's University Belfast - Research Portal:

Link to publication record in Queen's University Belfast Research Portal

\section{Publisher rights}

Copyright 2020 Elsevier.

This manuscript is distributed under a Creative Commons Attribution-NonCommercial-NoDerivs License

(https://creativecommons.org/licenses/by-nc-nd/4.0/), which permits distribution and reproduction for non-commercial purposes, provided the author and source are cited.

\section{General rights}

Copyright for the publications made accessible via the Queen's University Belfast Research Portal is retained by the author(s) and / or other copyright owners and it is a condition of accessing these publications that users recognise and abide by the legal requirements associated with these rights.

\section{Take down policy}

The Research Portal is Queen's institutional repository that provides access to Queen's research output. Every effort has been made to ensure that content in the Research Portal does not infringe any person's rights, or applicable UK laws. If you discover content in the Research Portal that you believe breaches copyright or violates any law, please contact openaccess@qub.ac.uk. 
2 hepatoprotective bioactives in freshwater clam (Corbicula fluminea Muller)

Zhaoshuo $\mathrm{Yu}^{1,3}$, Guanzhen $\mathrm{Gao}^{1}$, Huiqin Wang ${ }^{1}$, Lijing Ke ${ }^{1}$, Jianwu Zhou ${ }^{1}$, Pingfan $\mathrm{Rao}^{1}$, Tianbao Chen ${ }^{2}$, Zhangwen Peng ${ }^{1,3}$, Jianqiao Zou ${ }^{1,3}$, Sihao Luo ${ }^{1,3}$

1 SIBS-Zhejiang Gongshang University Joint Centre for Food and Nutrition Sciences, Zhejiang Gongshang University, Hangzhou, 310012, China

2 Natural Drug Discovery Group, School of Pharmacy, Queen's University Belfast, Belfast, Northern Ireland BT9 7BL, UK

3 Institute of Food Science, Jishou University, Jishou, 416000, Hunan, China

* Corresponding author: Lijing Ke, Ph.D., Associate Professor

Email: lijingke@zjgsu.edu.cn; Tel: +86 57188086706 


\section{Abstract}

5 Bioactives can impact food function either by their dosage or by their forms of dispersion,

6 though the latter remains mostly neglected. Here we report the incidental nanoparticles

7 (iNPs) carrying hepatoprotective bioactives identified in freshwater clam (Corbicula

8 fluminea Muller) soup, which is a folk remedy for liver conditions in East Asia. The soup

9 was fractionated into two iNPs containing fractions with high yield (95.8\%) in 35 min by

10 gel chromatography. With hydrodynamic diameter $\left(D_{h}\right)$ range from $40 \mathrm{~nm}$ to $149 \mathrm{~nm}$,

11 iNPs were mainly constituted by carbohydrates and proteins. Notably, the majority of

12 bioactives, e.g. taurine (63.2\%), ornithine (68.1\%) and phytosterols $(60.0 \%)$, was

13 determined to be carried by the iNPs. It suggested a possible mechanism of elevated

14 delivery and absorption of bioactives, explaining why the clam soup can work at the

15 bioactive concentrations way lower than the individual compound. These iNPs have great

16 potential to be developed into a functional food with most potent nutraceutical effects.

18 Keywords: Bioactives carrier; Freshwater clam soup; incidental nanoparticles 


\section{Introduction}

Shell fishes from the bivalve mollusc family are popular delicacy in many households and restaurants. Besides as a culinary delicacy, the freshwater clam (Corbicula fluminea Muller) has been used as a folk remedy for treating liver problems and hyperlipidemia, well proven by recent studies [1-4]. By cooking for $30 \sim 60 \mathrm{~min}$, the condensed freshwater clam soup was obtained, of which several phytosterols are proposed as the key bioactive compound. The pharmacological studies indicate that phytosterols could reduce lipid and cholesterol absorption from the intestine, promote sterol excretion and thus ameliorate hyperlipidemia and hepatic lipids [5]. Besides the phytosterols, ornithine and taurine also contribute to the therapeutic effects of the soup $[6]$.

Huang S., et al. [7] suggested that both the hot-water extract of freshwater clam (FCW) and proteinase hydrolysates of freshwater clam meat residues (FCWR) are effective against hypercholesterolemia of tilapia fed by a high-cholesterol diet. Intriguingly, FCW exhibited the similar amelioration with FCWR while its phytosterol content is one fourteenth of FCWR. The mechanistic explanation for FCW's potent bioactivity remains as a paradox.

Our previous study [8] has elucidated that the freshwater clam soup is a complex dispersion system containing solutes, colloids and aggregates. The prominent presence of self-assembled incidental nanoparticles (iNPs) [9] in the soup, however, suggests a new promising possibility. Similarly, the incidental and bioactive nanoparticles have been 
41 identified in many other foods including bone soup [10,11], tea [12], milk [13],vinegar $42[14]$ and in some Chinese herbal medicinal soup [15,16]. The bioactives have been found 43 to be carried by these iNPs, which might re-define the bioaccessibility, bioavailability and 44 thus function or efficacy. For instance, it was reported that the self-assembled nanoparticles of licorice protein carrying aconitine reduce the toxicity compared to single aconitine [15]; the self-assembly of berberine and flavonoid glycosides, widely used as

47 clinical antibacterial diarrhea exhibits stronger inhibition on bacteria population and biofilm [17]. Hence, the existing form and distribution of bioactives in foods can alter their functions. Yet, the distribution of bioactives in the freshwater clam soup remains unclear. To elucidate the physicochemical characteristics and biological activities of these iNPs, distinguishing them from other soluble components in food matrix, there is an urge to isolate the soup iNPs and analyze the bound bioactives.

However, the isolation of the iNPs from the complex food matrix as found in the soup with good yield and, if possible, minimal damage, remain a major challenge [18]. chromatography (SEC) are commonly employed [12]. While these methods separate particles according to their size, the NPs may be more susceptible to the shear force during ultrafiltration, resulting in clumping or agglomeration of NPs [19]. More importantly, dialysis or ultrafiltration is insufficient to separate and identify the iNPs in subgroups. By contrast, SEC coupled with light scattering detector satisfactorily separated and characterized iNPs subgroups in real time and in situ, exerting minor influence on their 
granular properties and bioactivities, as were demonstrated in iNPs from porcine bone soup [10] and Chinese herbal medicines [16]. In this study, a single-step and high yield nanoparticle isolation approach using SEC coupled with dynamic light scattering (DLS) was established and validated for selectively separation of functional iNPs from freshwater clam soup. A quantitative analysis based on DLS was established to estimate the yield of food iNPs. Furthermore, the granular properties and bounding states of the bioactives in the soup were determined.

\section{Materials and methods}

\subsection{Materials}

Freshwater clam (Corbicula fluminea Muller) was cultivated and collected from the LiChuan Aquaculture Farm, Hualien, Taiwan. The deionized water was obtained from Millipore Milli-Q water purification system (Millipore, Bedford, MA, USA). All the chemicals and solvents used were of AR grade and purchased from Sigma-Aldrich Co., Ltd. (Shanghai, China) and Sinopharm Chemical Reagent Co., Ltd, China. Sepharose CL4B column $\left(60 \mathrm{kDa}-2 \times 10^{4} \mathrm{kDa}\right)$ was purchased from Sinopharm Chemical Reagent Co., Ltd, China.

\subsection{Preparation of freshwater clam soup}

The clams were cultivated in cool water for $6 \mathrm{~h}$ and washed before cooking for 60 min with pure water $(1: 1, \mathrm{w} / \mathrm{v})$. The soup was pooled together and centrifuged at 5,000 $\mathrm{g}$ for $10 \mathrm{~min}$ to remove the solid residues. The supernatant was collected and stored at - 
$20^{\circ} \mathrm{C}$ until analyzed.

\subsection{Isolation of freshwater clam soup iNPs by DLS coupled SEC}

One milliliter soup was subjected to a pre-equilibrated (0.02 M phosphate buffer, pH 7.2) size-exclusive chromatographic column (Sepharose CL-4B, $1.0 \mathrm{~cm} \times 12 \mathrm{~cm}$ ) equipped with a UPLC (Chromatography System, BIO-RAD, USA) system at flow rate $0.5 \mathrm{~mL} / \mathrm{min}$, UV monitor at $280 \mathrm{~nm}$, coupled with a dynamic light scattering (DLS) instrument (Zetasizer Nano-ZS, Malven instruments Ltd, UK) equipped with a flow-cell. The elutes were collected by an automatic fraction collector (NGC Fraction Collector, BIO-RAD, USA) according to the light scattering intensity and UV absorbance at 280 nm. As shown in Fig 1, the fractions with strong light scattering or UV absorbance signals were collected and named as below: F1 (elution volume 6 to $12 \mathrm{~mL}$ ), F2 (elution volume 12 to $16 \mathrm{~mL}$ ) and $\mathrm{F} 3$ (elution volume 16 to $26 \mathrm{~mL}$ ).

Peak resolution (R) for the selected nanoparticles was calculated according to $\mathrm{C}$. Terriente, et al. [20]. Briefly, it was a function of retention time of the two peaks, $\mathrm{t}_{\mathrm{R} 1}$ and $\mathrm{t}_{\mathrm{R} 2}$, and the peak widths at half height, $\mathrm{W} 1_{1 / 2}$ and $\mathrm{W} 2_{1 / 2}$, of the analyte and another peak Eq.

$$
\mathrm{R}=1.18 \times\left(\frac{t_{R 2}-t_{R 1}}{W 1_{1 / 2}+W 2_{1 / 2}}\right)
$$

To determine whether there is a linear relationship between the light scattering and mass of the NPs, the soup was diluted for 1, 4, 16, 64, and 256 times and measured for their scattering intensity. The mass yield of SEC-NPs $(\mathrm{Y})$ were estimated according to the following equation: 
where $L C$ is the light scattering of NPs and $V$ is the volume of NPs fraction. Subscripts $i$ and $\mathrm{j}$ refer to each NPs fraction while $L C_{a}$ is the initial light scattering of $1 \mathrm{~mL}$ of the soup.

\subsection{Colloid properties of SEC-NPs}

The light scattering intensity, hydrodynamic diameter, polymer dispersity index

109

110

111

112

113

(PDI), and $\zeta$-potential of SEC-NPs were characterized by DLS with Zatasizer Nano-ZS

(Malven instruments Ltd, UK). One milliliter of the supernatant, without dilution, was gently injected to the cuvette for measurement at $25^{\circ} \mathrm{C}$. Viscosity of 0.8872 and refractive index (RI) of 1.330 were used in the measurement and analysis.

\subsection{Major composition analysis}

Protein content was determined by using Bicinchoninic acid (BCA) kit (Beyotime biotechnology, China), according to manufactory's protocol , and briefly, prepare the required amount of BCA Working Reagent and BSA protein standards of different concentrations $(0.025-0.5 \mathrm{mg} / \mathrm{mL})$, respectively. Add $200 \mu \mathrm{L}$ of the BCA Working Reagent and $20 \mu \mathrm{L}$ sample or BSA protein standard to $96-w e l l$ plate, followed by the incubation at $37^{\circ} \mathrm{C}$ for $30 \mathrm{~min}$. Then measure the absorbance of the solution at $562 \mathrm{~nm}$. Triglyceride content was determined with GPO-PAP assay (Sigma- Aldrich, USA), according to manufactory's protocol , and briefly, set up the Master Reaction Mix (Triglyceride Assay Buffer, Triglyceride Probe and Triglyceride Enzyme Mix) and then add $50 \mu \mathrm{L}$ Master Reaction Mix to each sample ,standard, and background control well containing the Triglyceride standard. For colorimetric assays, measure the absorbance at 
$570 \mathrm{~nm}$.

Polysaccharides content was tested by using anthrone-sulfuric acid assay. Briefly, add $0.5 \mathrm{~mL}$ samples or glucose standard of different concentrations $(0-80 \mu \mathrm{g} / \mathrm{mL})$ to $5 \mathrm{~mL}$ of anthrone reagent (anthrone $0.75 \%(\mathrm{w} / \mathrm{w})$ in analytical quality sulphuric acid $84 \%$ $(\mathrm{w} / \mathrm{v}))$. The samples were shaken with a Vortex mixer (Thermofisher, USA) to ensure complete uniformity of the dispersion and heated for exactly $10 \mathrm{~min}$ in a boiling-water bath. They were cooled in an ice-water bath and measured the absorbance at $590 \mathrm{~nm}$. Mass of each fraction was determined with gravimetric analysis of the freeze-dried samples.

\subsection{Nanoparticle Morphology}

TEM observation of iNPs from the soup were performed with JEOL JEM-1230 (TEM, Japan). The iNPs dispersion was transferred to the 230 mesh copper grid and airdried, observed under the TEM at $80 \mathrm{kV}$.

\subsection{Amino acid analysis of iNPs hydrolysates}

The amino acid composition of F1, F2, F3 and soup was determined according to the method described by Yang et al. [21]with a slight modification. It was determined by applying high performance liquid chromatography (HPLC, Waters, Milford, MA) coupled with cation exchange column $\left(\mathrm{Na}^{+}, 4.6 \mathrm{~mm}\right.$ ID $\left.\times 60 \mathrm{~mm}\right)$. The total amino acid compositions were determined after oven drying at $60^{\circ} \mathrm{C}$ for deacidify prior to hydrolysis at $110^{\circ} \mathrm{C}$ for $24 \mathrm{~h}$ with $6 \mathrm{M}$ hydrochloric acid. External standards (Sigma, St. Louis, MO, USA) of 17 amino acids and non-protein amino i.e. taurine and ornithine were used for 
quantification.

147

148

149

150

151

152

153

154

155

156

157

158

159

160

\subsection{Bioactive compound analysis}

F1, F2 and F3 were analyzed for phytosterol levels according to the method of K.

Warner et al. [22], using HPLC equipped with an ELSD, (model ELSD II, Varex Corp., Rockville, MD) and a reverse-phase $\mathrm{C}_{18}$ column (Resolve, $3.9 \mathrm{~mm} \times 15 \mathrm{~cm}$ )(Waters

Chromatographic Division, Milford, MA). The peaks of samples were identified by comparing with elution times of standards (brassicasterol, campesterol, stigmasterol, $\beta$ sitosterol and ergosterol, Sigma, St. Louis, MO, USA).

\subsection{Statistical analysis}

Data presented is the mean value and standard deviation obtained from three samples. Measurements were carried out in triplicates in determination of chemical compositions and granular properties. Significant differences were determined by $t$-test in Microsoft Office Excel. Significance was determined at $\mathrm{p}<0.05$. 


\section{Result and discussions}

\subsection{SEC separation of the soup nanoparticles}

Clam compositions gradually migrated into the aqueous phase during boiling and then self-assembled into nanoparticles with an average hydrodynamic diameter $\left(\mathrm{D}_{h}\right)$ of $75 \mathrm{~nm}$ and $\zeta$-potential of $-5.0 \mathrm{mV}$. The SEC coupled with DLS successfully separated three fractions from the complex food matrix of soup. The iNPs and non-particle compositions of soup were separated into two well-defined peaks by SEC-DLS within 50 min, of which the separation resolution was about 3.2, well above the standard resolution of 1.5 (a suitable value strongly recommended by AOAC International). As shown in Fig. 1, the first peak exhibited strong light scattering signals with a wide peak width and ultraviolet light absorbance at $280 \mathrm{~nm}$ while the second peak exhibited very weak light scattering but strong UV $280 \mathrm{~nm}$ absorbance. The first peak, marked as the colloidal particles, was further separated into two fractions for further analysis, namely F1 and F2. Two subgroups of iNPs were obtained accordingly with average $\mathrm{D}_{h}$ of $70.9 \mathrm{~nm}$ and 45.9 nm, respectively. The second peak, namely F3, was mainly consisted of small molecules with relatively strong ultraviolet absorbance, and minor proportion of iNPs. As shown in Tab.1, the light scattering of F1 fraction account for majority of the iNPs while the iNPs in F2 fraction was about one tenth of the F1 iNPs. The average hydrodynamic diameter of F1 iNPs was $25 \mathrm{~nm}$ larger than the F2 iNPs, with smaller PDI indicating a narrower size distribution. At $\mathrm{pH} 7.2, \mathrm{~F} 3$ fraction exhibited greater negative $\zeta$-potential than $\mathrm{F} 1$ and F2 fractions, indicating that the iNPs in F3 fraction may interact with the SEC 
182

chromatographic gel with greater ionic bonds and thereafter cause the delayed retention time compared to iNPs in earlier fractions, with which almost the same particle size was shared. TEM revealed spherical NPs in F1, while some ellipses and near-spherical NPs in F2 and F3 fractions (Fig. 2A). The mixture of iNPs and small molecules in F3 fraction indicates the chromatographic column used in this study is not efficient enough for full separation of nano-aggregates and other individual molecules (Fig. 2B). The SEC resolution could be improved by enlarging the length/diameter ratio of the column or change of chromatographic resin with finer capacity of separating molecules from nanoaggregates.

\subsection{Quantification and mass yield of the iNPs}

The light scattering is commonly used to quantify the number of nanoparticles [23] and was employed here for quantification of the nanoparticles in the soup and its fractions. The correlation of the mass (dry weight) and light scattering intensity of soup iNPs was determined with a serial of diluted soup samples. As shown in Fig 3, the mass concentration was linearly and positively correlated with the light scattering intensity of NPs with a $R^{2}$ value of 0.9959 . This result was rather satisfactory, taking into account that the other components in food matrix would have caused errors in the light scattering measurement and have damaged the accuracy of calculating particle number with light scattering intensity [18]. The light scattering-mass quantification equation offers an easy but relatively accurate quantification method for the iNPs. Accordingly, the recovery 
percentage of iNPs in F1 and F2 fractions was $95.83 \%$ determined by the light scattering

204

intensity, indicating the almost full recovery of iNPs separated with SEC approach. The precise number of particles could be further confirmed using Nanoparticle Tracking Analysis (NTA) [24]. The subtotal dry weight recovery rate of F1and F2 was 51.9\%, larger than that of F3 as shown in Tab. 1.

In addition, the iNPs remained almost the same size after the dilution or separation, indicating the minor influence of SEC separation on the iNPs' properties. The separation of soup iNPs can be scaled up by increasing the chromatographic column volume or elevating the sample concentration applied to the column.

\subsection{Composition analysis of iNPs}

As shown in Fig 4, the major chemical compositions (protein, carbohydrate and lipid) of the iNPs were identified. All the fractions and the dry matter of soup were mainly constituted by carbohydrates, proteins and lipids, while carbohydrates were the dominant composition and lipids the least. F1 exhibited the highest carbohydrate content among the fractions, while F3 are more dominant by protein and lipid. Given that carbohydrate and protein proportion of F1 and F2 (iNPs) exceeded 96\%, the boiling water extraction process of clam soup produced a novel protein-polysaccharide hybrid nanostructure. A small amount of lipid most possibly bound to the hydrophobic domains of the hybrids. Several studies reported health-promoting polysaccharides in the soup, or say boiling water extracts, of freshwater clams. For instance, proteoglycan CFPS-2 [25] with 
an average molecular weight of $22 \mathrm{kDa}$ exhibited strong antioxidant activities and inhibitory effects on proliferation of human gastric cancer cells. Apart from strong antioxidant capacity, CFPS-11(807.7 kDa)[26] remarkably inhibited $\alpha$-amylase and $\alpha$ glucosidase. Although there is no complete dissection of the iNPs' protein compositions, a dominant protein with molecules weight of $37 \mathrm{kDa}$ was revealed by SDS-PAGE [8]. Since molluscs, including the freshwater clam, were generally rich in polysaccharides [27], proteins and lipids, it is expectable to find the supramolecular complexes or nanostructures in the boiling water extracts of many other molluscs.

As shown in Tab. 2, seventeen kinds of amino acids were found in the soup and its fractions, while forty percent of which were essential amino acids. The amino acid compositions of the iNPs containing fractions were similar with those of the soup, in which glutamic acid contributed the highest proportion. Besides, a rather high amount of asparagine, arginine and serine were found in the iNPs. The total amino acids of F1 and F2 fractions was $2.6 \mathrm{mg} / \mathrm{mL}$, determined by HPLC, significantly higher than their total protein content $1.8 \mathrm{mg} / \mathrm{mL}$, determined by BCA assay, clearly indicating the existence of a significant amount of free amino acids. This is a rather unusual since the amino acids were small molecules and not supposed to be eluted together with particles in the gel filtration separation. The only logical explanation is these amino acids were bound to the iNPs in these two fractions. In contrary, the total amino acids of F3 fraction was 2.7 $\mathrm{mg} / \mathrm{mL}$, which is less than its protein content $(3.2 \mathrm{mg} / \mathrm{mL})$. The abnormally high protein content of F3 fraction may be caused by its higher lipid contents or other reducing 
components. In fact, the presence of lipids might give excessively high absorbance with this assay [28].

More than $65 \%$ of the constituent amino acids of the iNPs fractions (F1 and F2) were flavor-related amino acids (e.g. glutamic acid, serine, arginine, glycine, alanine, leucine and lysine)[27], indicating a possible contribution of iNPs to the palatability of soup. It remains unclear whether the presence of iNPs would have affected the sensory profiles of these amino acids.

Taurine and ornithine are two non-protein, not essential amino acids found in the clams, with many health promoting effects. Taurine is one of the predominant amino acids in muscle tissue, plays an important role in battling oxidative stress-induced inflammation [29]. As the major amino acid of oyster extracts, taurine attenuated non-alcoholic steatohepatitis (NASH) mouse [30]. Similarly, ornithine has long been claimed to be beneficial for liver [6], promote the secretion of the growth hormone and muscle building. Thus, taurine and ornithine are popularly used in dietary supplements [31,32].

Their contents in the soup and its separated fractions were determined, as shown in Fig 4. It was found that the proportions of taurine and ornithine in the first two fractions (F1 and F2) were $63.2 \%$ and $68.1 \%$, respectively. For the same reason discussed earlier on the free amino acids, it elucidated that a significant amount of taurine and ornithine were bound to and carried by the iNPs. The existing status of taurine and ornithine in the third fraction (F3) remained undetermined as the co-existence of small molecules and the minor amount of iNPs. The soup iNPs could serve as carrier for hydrophilic payloads 
with small molecular weights, e.g. amino acids and their derivatives.

Besides the hydrophilic amino acids, phytosterols were also reported to be active components of the clam soup [2]. Similar to taurine and ornithine, these hydrophobic compounds were found in all three SEC fractions of clam soup. As shown in Fig. 4, the total content of brassicasterol was the highest, followed by that of campesterol, stigmasterol, $\beta$-sitosterol and ergosterol. It was illuminated that $60 \%$ of phytosterols were

found in the iNPs containing fractions (F1 and F2). Similar to free amino acids, the chromatographic behavior of these phytosterols elucidated the encapsulation of phytosterols in the iNPs. In contrast, the phytosterols in F3 fraction might form micelles or bind to co-existing amphiphilic compounds, therefore be at least part of the nanoparticles in this fraction.

The lipid components of freshwater clam extracts, including phytosterols, had been demonstrated to have potent hypolipidemic effects in dyslipidaemia and atherosclerosis $[5,33]$. Recently we have reported the iNPs derived from the freshwater clam soup ameliorated non-alcoholic fatty liver in Meriones unguieulataus by both oral and gastric administrations [34]. Therefore, the taurine, ornithine and phytosterols carried by the iNPs might be contributing to their hepatoprotective and hypolipidemic effects. However, the retrieved bioactive contents from the soup were not in the same order of the clinically effective dosages of taurine [35], ornithine [36] and phytosterols [5], which are above 6 g/day, 12 g/day and 9 g/day, separately. It remains unknown whether synergetic effects, elevated bioavailability or targeted delivery make the major contribution to the higher 
287

288

289

290

291

292

293

294

295

296

297

298

299

300

301

302

303

304

305

306

307

308

efficiency of the clam soup. It would be worthwhile to investigate whether the iNPs elevate the bioavailability, targeted delivery and release and subsequently enhance therapeutic effects of these small molecule bioactives, as have been widely reported in many nano-carriers for nutrients and drugs [37]. Nanoparticle encapsulation has been reported to elevate the bioavailability of phytosterols [38]. The mucosal enterocytes and macrophages on the surface of alimentary tract show preference to the uptake of exogenous particulate matter, including food micro-/nano-particles [11], polymerized liposomes [39] and self-assembled peptide NPs for drug oral delivery [40]. Intermediated by these cells, the bioactives carried by the clam soup iNPs can be absorbed and transported more efficiently. On the other hand, the digestible scaffolds of the clam soup iNPs, made of carbohydrates, proteins and lipids, could be gradually degraded in response to the digestive enzymes in different segments of alimentary tract and therefore allow the control-release of payload bioactives to occur.

\section{Conclusions}

In conclusion, the protein-polysaccharide iNPs were successfully isolated from the freshwater clam soup by one-step DLS coupled gel filtration with high yield and minimal damage. Bioactive compounds, i.e. taurine, ornithine and several phytosterols, were demonstrated to be carried by the iNPs, which might have a profound effect on their delivery, bioavailability and therapeutic effects. Moreover, it reveals the food derived iNPs can be promising nano-vehicles for bioactive payload, and developed into a new category of functional ingredients for applications in food and medicine. 


\section{Acknowledgement}

310

311

312

This study was supported by the National Key R\&D Program of China (2016YFD0400202), and National Natural Science Foundation of China (Grant No. $31571803)$.

\section{Notes}

The authors declare no competing financial interest.

\section{References}

[1] J.J. Lin, Y.C. Liu, C.J. Chang, M.H. Pan, M.F. Lee, B.S. Pan, Hepatoprotective mechanism of freshwater clam extract alleviates non-alcoholic fatty liver disease: elucidated in vitro and in vivo models, Food Funct. 9 (2018) 6315-6325. doi:10.1039/c8fo01758a.

[2] T. Chijimatsu, I. Tatsuguchi, H. Oda, S. Mochizuki, A freshwater clam (corbicula fluminea) extract reduces cholesterol level and hepatic lipids in normal rats and xenobiotics-induced hypercholesterolemic rats, J. Agric. Food Chem. 57 (2009) 3108-3112. doi:10.1021/jf803308h.

[3] T. Chijimatsu, I. Tatsuguchi, K. Abe, H. Oda, S. Mochizuki, A freshwater clam ( Corbicula fluminea ) extract improves cholesterol metabolism in rats fed on a high-cholesterol diet, Biosci. Biotechnol. Biochem. 72 (2008) 2566-2571. doi:10.1271/bbb.80257.

[4] Y.H. Lin, J.S. Tsai, L.B. Hung, B.S. Pan, Hypocholesterolemic effect of compounded freshwater clam protein hydrolysate and Gracilaria, Food Chem. 123 (2010) 395-399. doi:10.1016/j.foodchem.2010.04.053.

[5] L. Song, D. Qu, Q. Zhang, H. Zhou, R. Jiang, Y. Li, Phytosterol esters attenuate hepatic steatosis 
in rats with non- alcoholic fatty liver disease rats fed a high-fat diet, Sci. Rep. 7 (2017) 1-14. doi:10.1038/srep41604.

[6] A. Canbay, J.P. Sowa, L-Ornithine L-Aspartate (LOLA) as a Novel Approach for Therapy of Non-alcoholic Fatty Liver Disease, Drugs. 79 (2019) 39-44. doi:10.1007/s40265-018-1020-5.

S.C. Huang, J.J. Lin, M.F. Lee, Y.C. Liu, B.S. Pan, Freshwater clam extracts alleviate dyslipidaemia of tilapia fed a high-fat diet as an animal model, J. Funct. Foods. 25 (2016) 559567. doi:10.1016/j.jff.2016.06.017.

[8] L. Ke, J. Zhou, W. Lu, G. Gao, P. Rao, The power of soups: Super-hero or team-work?, Trends Food Sci. Technol. 22 (2011) 492-497. doi:10.1016/j.tifs.2011.06.004.

[9] M.F. Hochella, D.W. Mogk, J. Ranville, I.C. Allen, G.W. Luther, L.C. Marr, B.P. McGrail, M. Murayama, N.P. Qafoku, K.M. Rosso, N. Sahai, P.A. Schroeder, P. Vikesland, P. Westerhoff, Y. Yang, Natural, incidental, and engineered nanomaterials and their impacts on the Earth system, Science (80-. ). 363 (2019). doi:10.1126/science.aau8299.

[10] H. Wang, G. Gao, L. Ke, J. Zhou, P. Rao, Y. Jin, L. He, Q. Wang, Q. Wang, Isolation of colloidal particles from porcine bone soup and their interaction with murine peritoneal macrophage, J. Funct. Foods. 54 (2019) 403-411. doi:10.1016/j.jff.2019.01.021.

[11] L. Ke, H. Wang, G. Gao, P. Rao, L. He, J. Zhou, Direct interaction of food derived colloidal micro/nano-particles with oral macrophages, Npj Sci. Food. 1 (2017). doi:10.1038/s41538-0170003-3.

[12] S. Yi, Y. Wang, Y. Huang, L. Xia, L. Sun, S.C. Lenaghan, M. Zhang, Tea nanoparticles for immunostimulation and chemo-drug delivery in cancer treatment, J. Biomed. Nanotechnol. 10 
[13] C.M. Beliciu, C.I. Moraru, Effect of solvent and temperature on the size distribution of casein micelles measured by dynamic light scattering, J. Dairy Sci. 92 (2009) 1829-1839. doi:10.3168/jds.2008-1467.

[14] L. Cao, X. Song, Y. Song, J. Bi, S. Cong, C. Yu, M. Tan, Fluorescent nanoparticles from mature vinegar: their properties and interaction with dopamine, Food Funct. 8 (2017) 4744-4751. doi:10.1039/C7FO01475A.

[15] L. Ke, G. Gao, Y. Shen, J. Zhou, P. Rao, Encapsulation of Aconitine in Self-Assembled Licorice Protein Nanoparticles Reduces the Toxicity In Vivo, Nanoscale Res. Lett. 10 (2015) 1-8. doi:10.1186/s11671-015-1155-1.

[16] J. Zhou, G. GaO, Q. Chu, H. Wang, P. Rao, L. Ke, Chromatographic isolation of nanoparticles from Ma-Xing-Shi-Gan-Tang decoction and their characterization, J. Ethnopharmacol. 151 (2014) 1116-1123. doi:10.1016/j.jep.2013.12.029.

[17] T. Li, P. Wang, W. Guo, X. Huang, X. Tian, G. Wu, B. Xu, F. Li, C. Yan, X.-J. Liang, H. Lei, Natural Berberine-Based Chinese Herb Medicine Assembled Nanostructures with Modified Antibacterial Application, ACS Nano. (2019) acsnano.9b01346. doi:10.1021/acsnano.9b01346.

[18] F. von der Kammer, S. Legros, T. Hofmann, E.H. Larsen, K. Loeschner, Separation and characterization of nanoparticles in complex food and environmental samples by field-flow fractionation, TrAC - Trends Anal. Chem. 30 (2011) 425-436. doi:10.1016/j.trac.2010.11.012.

[19] A.N. Böing, E. van der Pol, A.E. Grootemaat, F.A.W. Coumans, A. Sturk, R. Nieuwland, Singlestep isolation of extracellular vesicles by size-exclusion chromatography, J. Extracell. Vesicles. 3 
(2014). doi:10.3402/jev.v3.23430.

[20] C. Terriente-Palacios, I. Diaz, M. Castellari, A validated ultra-performance liquid chromatography with diode array detection coupled to electrospray ionization and triple quadrupole mass spectrometry method to simultaneously quantify taurine, homotaurine, hypotaurine and amino acids in macro- and mic, J. Chromatogr. A. 1589 (2019) 83-92. doi:10.1016/j.chroma.2018.12.058.

[21] B. Yang, H. Yang, J. Li, Z. Li, Y. Jiang, Amino acid composition, molecular weight distribution and antioxidant activity of protein hydrolysates of soy sauce lees, Food Chem. 124 (2011) 551555. doi:10.1016/j.foodchem.2010.06.069.

[22] K. Warner, T.L. Mounts, Analysis of tocopherols and phytosterols in vegetable oils by HPLC with evaporative light-scattering detection, J. Am. Oil Chem. Soc. 67 (1990) 827-831. doi:10.1007/BF02540500.

[23] A. Gámez-Valero, M. Monguió-Tortajada, L. Carreras-Planella, M. Franquesa, K. Beyer, F.E. Borràs, Size-Exclusion Chromatography-based isolation minimally alters Extracellular Vesicles’ characteristics compared to precipitating agents, Sci. Rep. 6 (2016) 1-9. doi:10.1038/srep33641.

[24] V. Filipe, A. Hawe, W. Jiskoot, Critical evaluation of nanoparticle tracking analysis (NTA) by NanoSight for the measurement of nanoparticles and protein aggregates, Pharm. Res. 27 (2010) 796-810. doi:10.1007/s11095-010-0073-2.

[25] N. Liao, S. Chen, X. Ye, J. Zhong, N. Wu, S. Dong, B. Yang, D. Liu, Antioxidant and anti-tumor activity of a polysaccharide from freshwater clam, Corbicula fluminea, Food Funct. 4 (2013) 539-548. doi:10.1039/c2fo30178d. 
393

394

395

[26] K. Yan, Y. Wang, W. Qiu, L.Wu, Z. Ding, W. Cai, Purification, structural characterization and bioactivity evaluation of a novel proteoglycan produced by Corbicula fluminea, Carbohydr. Polym. 176 (2017) 11-18. doi:10.1016/j.carbpol.2017.08.063.

[27] Z.G. Rosas-Romero, J.C. Ramirez-Suarez, R. Pacheco-Aguilar, M.E. Lugo-Sánchez, G. CarvalloRuiz, G. García-Sánchez, Partial characterization of an effluent produced by cooking of Jumbo squid (Dosidicus gigas) mantle muscle, Bioresour. Technol. 101 (2010) 600-605. doi:10.1016/j.biortech.2009.08.074.

[28] W. JM, The Bicinchoninic Acid (BCA) Assay for Protein Quantitation, in: Protein Protoc. Hand B., 1996: pp. 11-14. doi:10.1007/978-1-60327-259-9_3.

[29] N.J. Mezzomo, B.D. Fontana, T.E. Müller, T. Duarte, V.A. Quadros, J. Canzian, A. Pompermaier, S.M. Soares, G. Koakoski, V.L. Loro, D.B. Rosemberg, L.J.G. Barcellos, Taurine modulates the stress response in zebrafish, Horm. Behav. 109 (2019) 44-52. doi:10.1016/j.yhbeh.2019.02.006.

[30] M. Watanabe, H. Fuda, H. Okabe, S. Joko, Y. Miura, S.P. Hui, Yimin, N. Hamaoka, E. Miki, H. Chiba, Oyster extracts attenuate pathological changes in non-alcoholic steatohepatitis (NASH) mouse model, J. Funct. Foods. 20 (2016) 516-531. doi:10.1016/j.jff.2015.11.029.

[31] G. Kircheis, R. Nilius, C. Held, H. Berndt, M. Buchner, R. Görtelmeyer, R. Hendricks, B. Krüger, B. Kuklinski, H. Meister, H.J. Otto, C. Rink, W. Rösch, S. Stauch, Therapeutic efficacy of Lornithine-L-aspartate infusions in patients with cirrhosis and hepatic encephalopathy: Results of a placebo-controlled, double-blind study, Hepatology. 25 (1997) 1351-1360. doi:10.1002/hep.510250609. 
414

[32] H. Uchisawa, A. Sato, J. Ichita, h. Matsue, T. Ono, Influence of Low-temperature Processing of the Brackish-water Bivalve, Corbicula japonica, on the Ornithine Content of Its Extract, Biosci. Biotechnol. Biochem. 68 (2004) 1228-1234. doi:10.1271/bbb.68.1228.

[33] T. Chijimatsu, M. Umeki, Y. Kataoka, S. Kobayashi, K. Yamada, H. Oda, S. Mochizuki, Lipid components prepared from a freshwater Clam (Corbicula fluminea) extract ameliorate hypercholesterolaemia in rats fed high-cholesterol diet, Food Chem. 136 (2013) 328-334. doi:10.1016/j.foodchem.2012.08.070.

[34] Z. Yu, H. Wang, G. Gao, L. Ke, J. Zhou, P. Rao, Improving Effects of Freshwater Clam Soup Nanoparticles on Non-Alcoholic Fatty Liver Disease of Meriones Unguieulataus, J. Chinese Inst. Food Sci. Technol. (2019). doi:10.1108/nfs.2008.01738dab.014.

[35] K. Obinata, T. Maruyama, M. Hayashi, T. Watanabe, H. Nittono, Effect of Taurine on the Fatty Liver of Children with Simple Obesity, in: Taur. 2, 1996: pp. 607-613. doi:10.1007/978-1-48990182-8_67.

[36] T. Yan, L. Gen, C. Tang, X. Yan, H. Luo, S. Tan, Z. Pang, Y. Zhang, L. Gong, Y. Li, S. Chen, J. Shi, Aspartate-ornithine granules in the treatment of nonalcoholic steatohepatitis: a multiple-dose parallel controlled clinical trial, Chinese J. Hepatol. 21 (2013) 528-532. doi: $10.3760 /$ cma.j.issn.1007-3418.2013.07.013

[37] A.R. Patel, Functional and Engineered Colloids from Edible Materials for Emerging Applications in Designing the Food of the Future, Adv. Funct. Mater. 1806809 (2018) 1-34. doi:10.1002/adfm.201806809.

[38] V. Raikos, V. Ranawana, Designing emulsion droplets of foods and beverages to enhance 

Technol. (2016) 1-13. doi:10.1111/ijfs.13272.

437

[39] K. Park, I. Chan, K. Park, Oral protein delivery : Current status and future prospect, React. Funct. Polym. 71 (2011) 280-287. doi:10.1016/j.reactfunctpolym.2010.10.002.

439

[40] Shan, W., Zhu, X., Liu, M., Li, L., Zhong, J., Sun, W., ... Huang, Y. Overcoming the Diffusion Barrier of Mucus and Absorption Barrier of Epithelium by Self-Assembled Nanoparticles for Oral Delivery of Insulin, ACS Nano. 9 (2015) 2345-2356. doi:10.1021/acsnano.5b00028. 9(3). 


\section{Figure captions}

Figure 1. Isolation of the edible nanoparticles in freshwater clam soup with combination of size-exclusive chromatography (SEC) and dynamic light scattering (DLS). Freshwater clam soup were fractioned by a Sepharose CL-4B column $(1.0 \mathrm{~cm} \times 12 \mathrm{~cm})$ equilibrated with $0.02 \mathrm{M}$ phosphate buffer ( $\mathrm{pH}$ 7.2) and eluted at a flow rate of $0.5 \mathrm{~mL} / \mathrm{min}$ with $\mathrm{UV}$ (absorbance at 280 $\mathrm{nm}$, solid line) and DLS detector (dash line). Inserted image: the hydrodynamic diameter of the colloidal nanoparticles determined by the Zetasizer Nano-ZS. Hydrodynamic diameter distribution of the soup and fractions obtained.

Figure 3. The relationship between concentration-light scattering of NPs in the soup. The soup was diluted for $1,4,16,64$, and 256 times with distilled water and their scattering intensity was then measured.

Figure 4. Major compositions and bioactives of fractions obtained. (A) Carbohydrate, protein and of the fractions obtained by SEC. (C) Phytosterol (e.g. brassica sterol, campesterol, stigmasterol, $\beta$-sitosterol and ergosterol) content of the fractions obtained by SEC. 
466 Table 1: Colloidal properties of soup, and all fractions (F1, F2 and F3) isolated by SEC.

\begin{tabular}{lcccc}
\hline & Clam soup & F1 & F2 & F3 \\
\hline $\begin{array}{l}\text { Hydrodynamic } \\
\text { diameter (nm) }\end{array}$ & $74.82 \pm 0.68^{*}$ & $70.86 \pm 1.82$ & $45.88 \pm 4.16^{* *}$ & $50.35 \pm 9.67^{* *}$ \\
$\begin{array}{l}\text { Light scattering } \\
\text { (Kcps) }\end{array}$ & $530056.4 \pm 1674.0^{* *}$ & $79992.1 \pm 248.5$ & $7011.9 \pm 113.8^{* *}$ & $1955.9 \pm 314.8^{* *}$ \\
PDI & $0.18 \pm 0.01$ & $0.16 \pm 0.01$ & $0.21 \pm 0.05$ & $0.27 \pm 0.02^{* *}$ \\
$\zeta$-Potential (mV) & $-4.90 \pm 0.86^{*}$ & $-7.29 \pm 0.59$ & $-5.40 \pm 1.32$ & $-15.10 \pm 1.55^{* *}$ \\
Mass Recovery $(\mathrm{mg})$ & 32.00 & 12.40 & 4.20 & 11.10 \\
\hline
\end{tabular}

479 $* \mathrm{p}<0.05$ vs. $\mathrm{F} 1$ and $* * \mathrm{p}<0.01$ vs. $\mathrm{F} 1$. 
Table 2: Total amino acids composition analysis of soup, and all fractions (F1, F2 and F3)

481 isolated by SEC.

482

483

484

485

486

487

488

489

490

491

492

493

494

495

496

497

498

499

500

501

502

503

504

505

\begin{tabular}{ccccc}
\hline $\begin{array}{c}\text { Amino acids } \\
\text { (mg/mL) }\end{array}$ & F1 & F2 & F3 & Clam soup \\
\hline Glu & 0.33 & 0.27 & 0.69 & 1.04 \\
Asp & 0.08 & 0.07 & 0.16 & 0.72 \\
Ser & 0.10 & 0.09 & 0.17 & 0.44 \\
Val & 0.08 & 0.07 & 0.15 & 0.43 \\
Arg & 0.14 & 0.13 & 0.28 & 0.37 \\
Gly & 0.08 & 0.07 & 0.12 & 0.29 \\
Leu & 0.10 & 0.08 & 0.17 & 0.29 \\
Lys & 0.10 & 0.07 & 0.17 & 0.27 \\
Pro & 0.04 & 0.04 & 0.08 & 0.23 \\
Thr & 0.06 & 0.05 & 0.10 & 0.22 \\
Ile & 0.06 & 0.04 & 0.10 & 0.22 \\
Tyr & 0.07 & 0.06 & 0.14 & 0.21 \\
Phe & 0.05 & 0.04 & 0.09 & 0.14 \\
Ala & 0.08 & 0.07 & 0.15 & 0.11 \\
His & 0.01 & 0.01 & 0.03 & 0.06 \\
Met & 0.03 & 0.02 & 0.05 & 0.05 \\
Cys & 0.02 & 0.02 & 0.04 & 0.04 \\
Total & 1.43 & 1.18 & 2.67 & 5.13 \\
Essential & 0.62 & 0.50 & 1.13 & 2.04 \\
\hline
\end{tabular}


Fig.1.

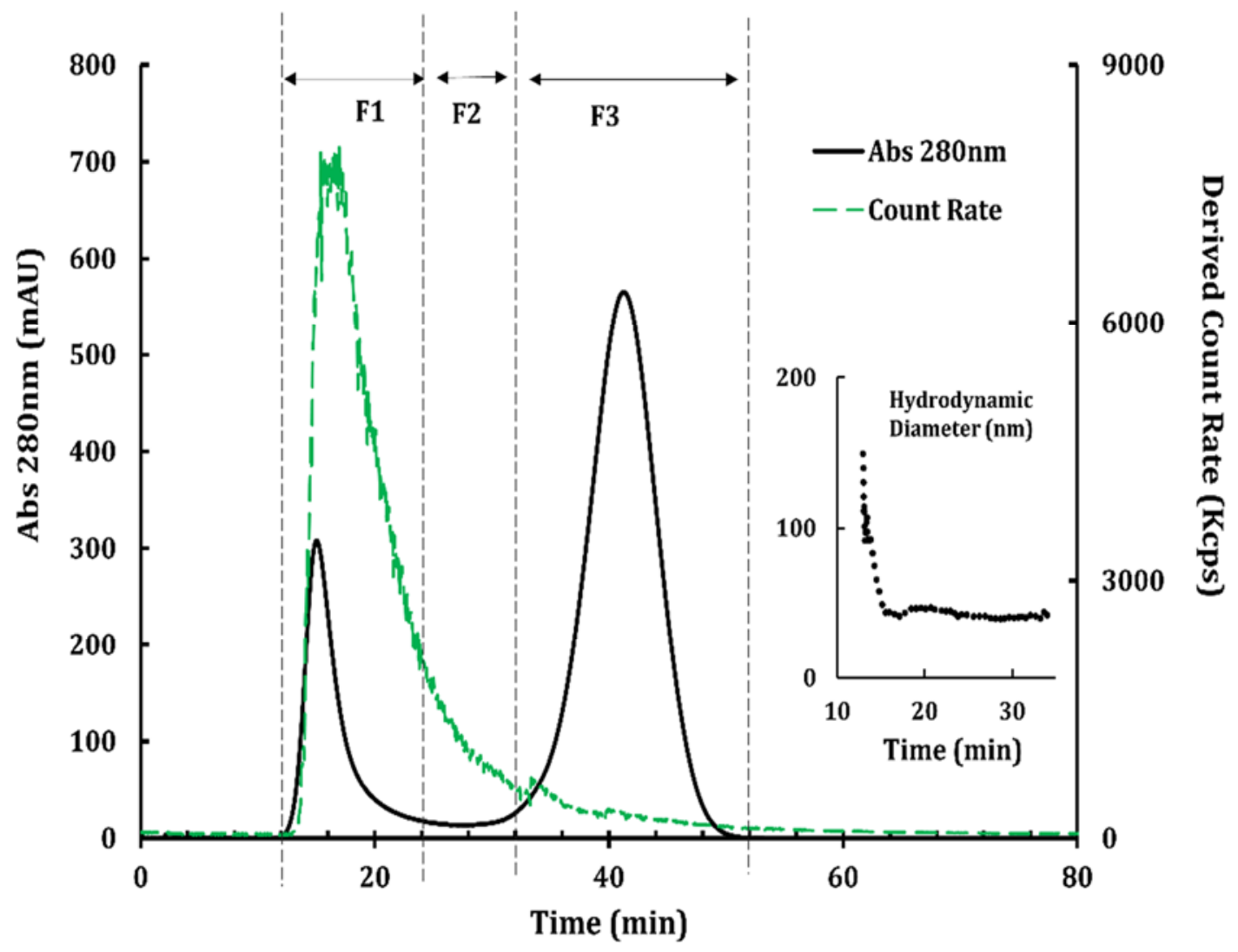


508

509

510

511

512

513

514

515

516

517

518

519

520

521

522

523

524

525

526

527

528

529

530

531

532

533
Fig.2.

(A)
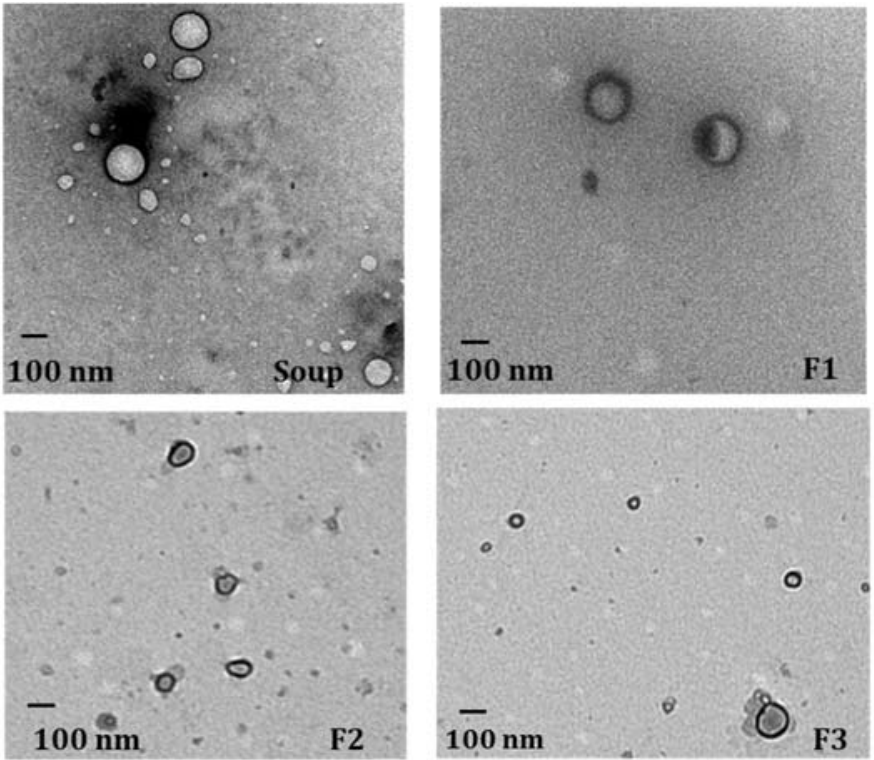

(B)

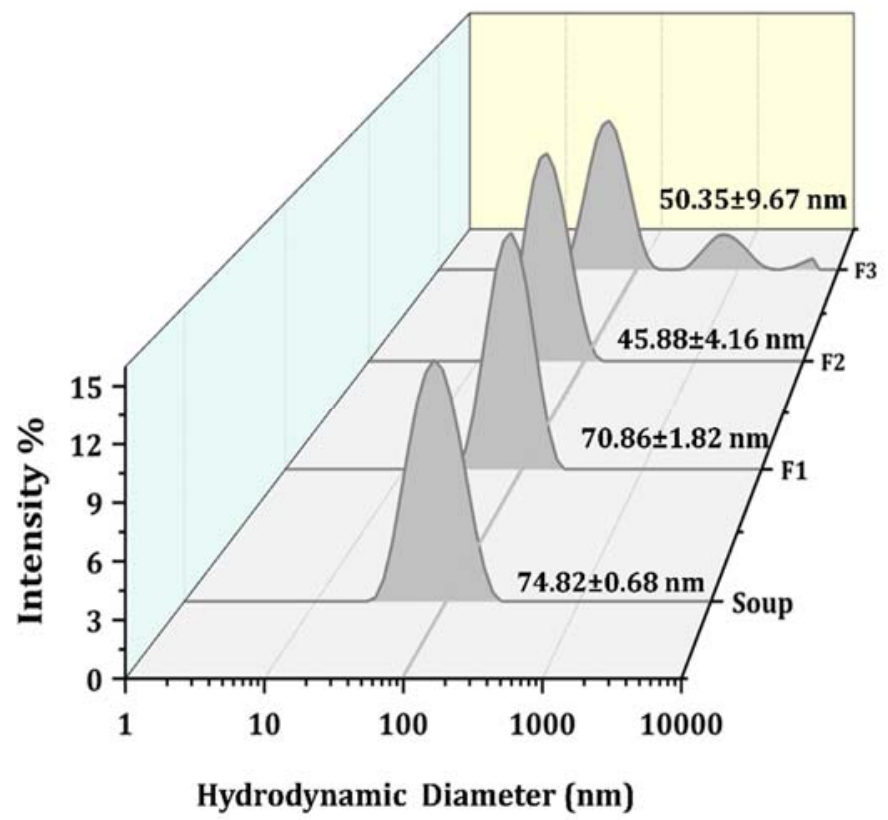

Hydrodynamic Diameter (nm) 
Fig.3.

535

536

537

538

539

540

541

542

543

544

545

546

547

548

549

550

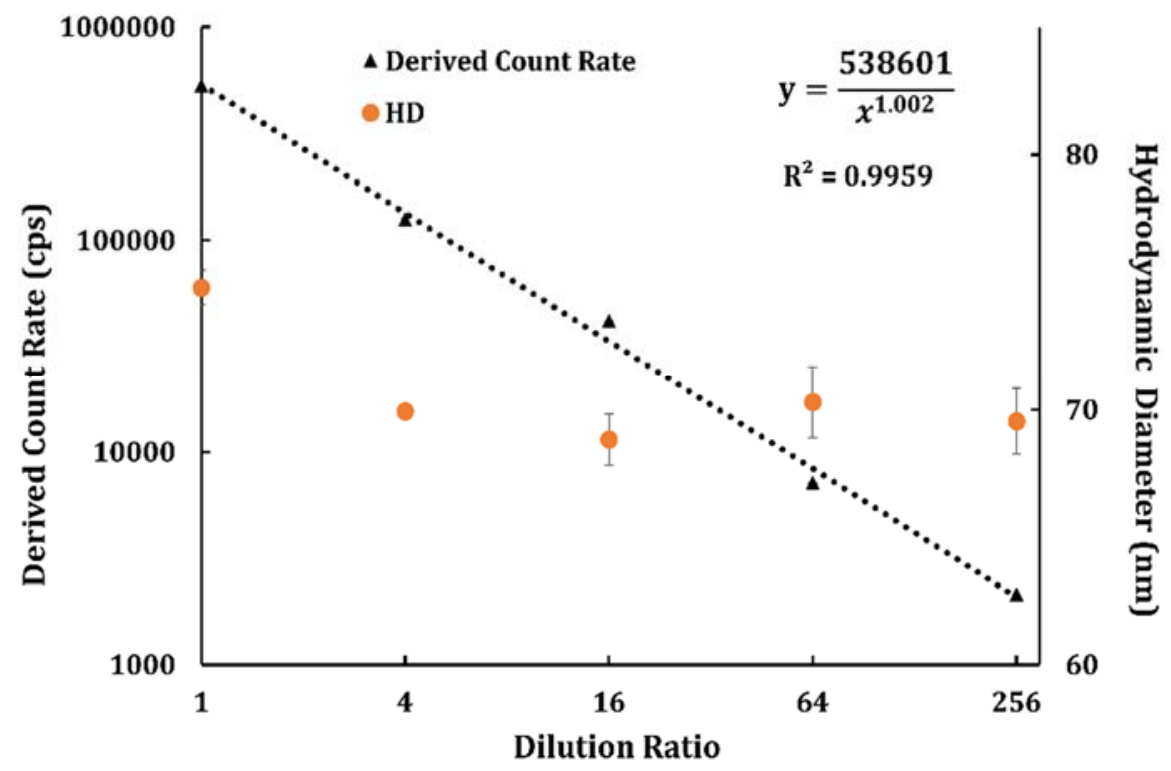


551

552

553

554

555

556

557

558

559

560

561

562

563

564

565

566

567

568

569

570

571

572

573

574

575

576
Fig.4.

(A)

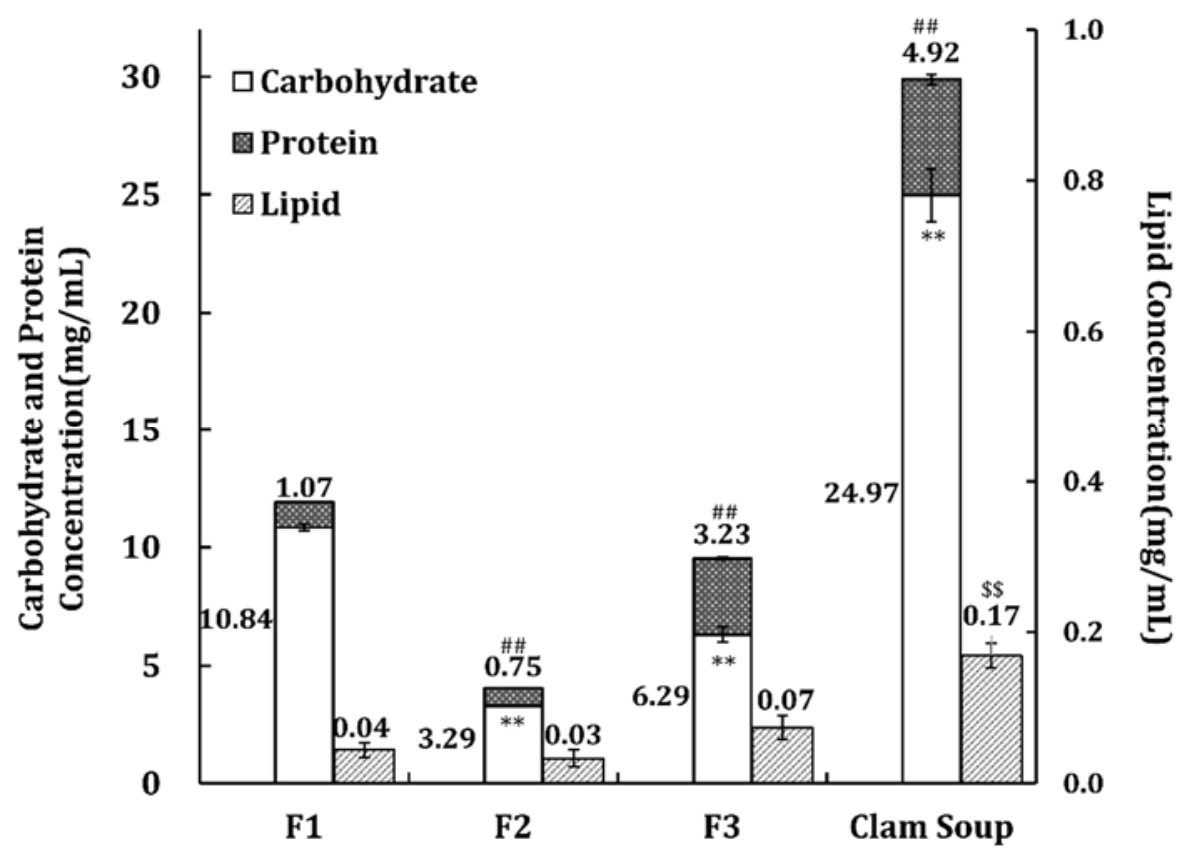

(B)

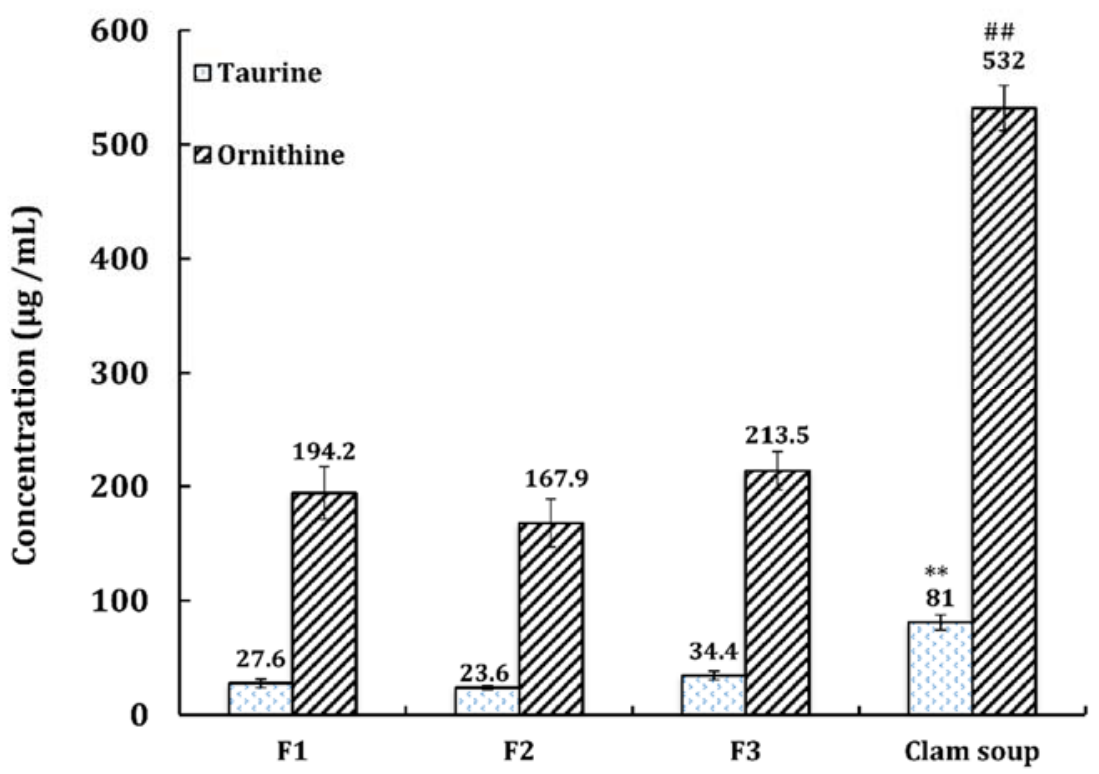


577

578

579

580

581

582

583

584

585

586

587

588

589

590

591
(C)

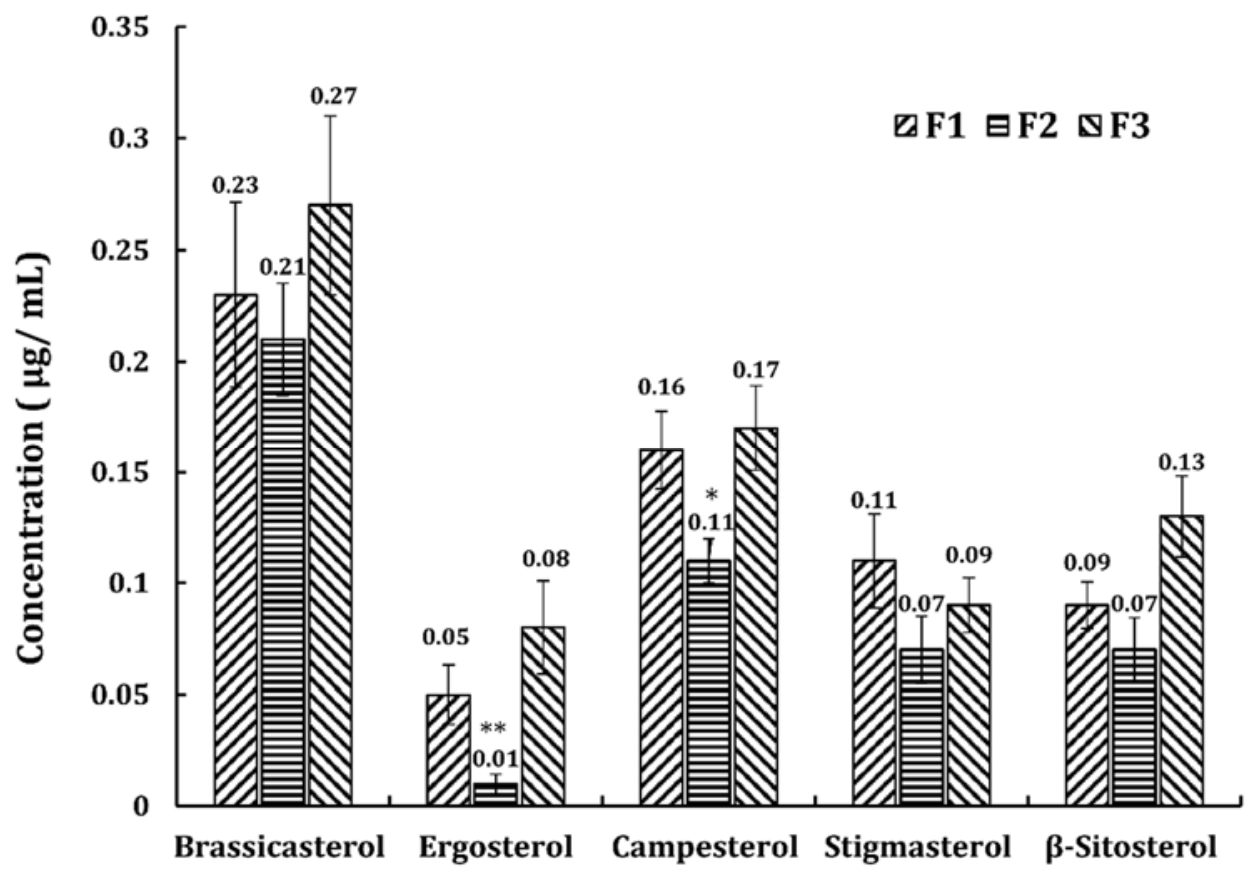




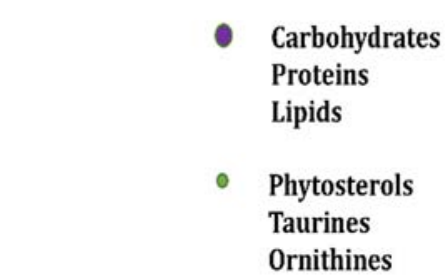

Freshwater Clam
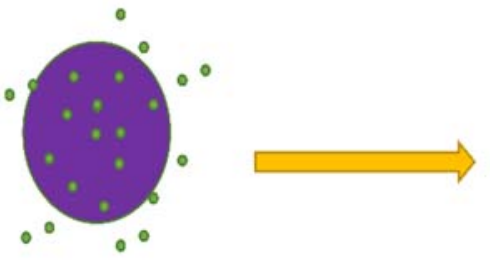

Nanoparticles

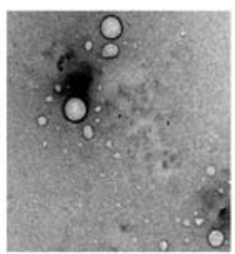

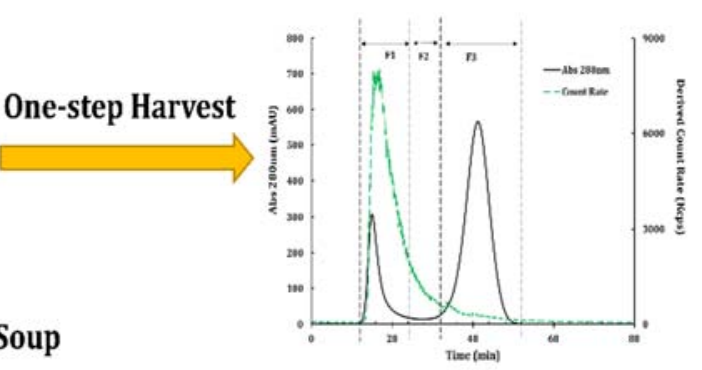

